\title{
Developing Behavioral and Evidence-Based Programs for Wildfire Risk Mitigation
}

\author{
Hilary Byerly ${ }^{1, *} \mathbb{( D}$, James R. Meldrum ${ }^{2}{ }^{\mathbb{D}}$, Hannah Brenkert-Smith $\left.{ }^{1} \mathbb{(}\right)$, Patricia Champ ${ }^{3}$, \\ Jamie Gomez ${ }^{4}$, Lilia Falk ${ }^{4}$ and Chris Barth ${ }^{5}$ \\ 1 Institute of Behavioral Science, University of Colorado Boulder, Boulder, CO 80309, USA; \\ hannahb@colorado.edu \\ 2 Fort Collins Science Center, U.S. Geological Survey, Fort Collins, CO 80526, USA; jmeldrum@usgs.gov \\ 3 Rocky Mountain Research Station, USDA Forest Service, Fort Collins, CO 80526, USA; \\ patricia.a.champ@usda.gov \\ 4 West Region Wildfire Council, Montrose, CO 81401, USA; jamie.gomez@cowildfire.org (J.G.); \\ lilia.falk@cowildfire.org (L.F.) \\ 5 Fire and Aviation Management, Bureau of Land Management, Billings, MT 59105, USA; cbarth@blm.gov \\ * Correspondence: hilary.b@colorado.edu; Tel.: +1-303-492-8147
}

Received: 7 October 2020; Accepted: 9 November 2020; Published: 11 November 2020

\begin{abstract}
The actions of residents in the wildland-urban interface can influence the private and social costs of wildfire. Wildfire programs that encourage residents to take action are often delivered without evidence of effects on behavior. Research from the field of behavioral science shows that simple, often low-cost changes to program design and delivery can influence socially desirable behaviors. In this research report, we highlight how behavioral science and experimental design may advance efforts to increase wildfire risk mitigation on private property. We offer an example in which we tested changes in outreach messaging on property owners' interest in wildfire risk information. In partnership with a regional wildfire organization, we mailed 4564 letters directing property owners to visit personalized wildfire risk webpages. By tracking visitation, we observed that 590 letter recipients (12\%) sought information about their wildfire risk and response varied by community. This research-practice collaboration has three benefits: innovation in outreach, evidence of innovation through experimental design, and real impacts on interest in wildfire mitigation among property owners. Future collaborations may inform behavioral and evidence-based programs to better serve residents and the public interest as the risks from wildfires are projected to grow.
\end{abstract}

Keywords: behavioral science; wildfire risk; private property; outreach communication; field experiment; research-practice collaboration

\section{Introduction}

In communities at risk of wildfire, mitigation on private property can improve personal safety and structure survivability [1,2]. Research suggests that wildland-urban interface (WUI) residents often report taking action to mitigate wildfire risk [3,4]. However, it is not clear that all efforts by residents are effective; research has also found that residents may view their parcels as better mitigated than a wildfire professional [5]. Wildfire mitigation and education programs encourage mitigation, ranging from broad federal efforts (e.g., Firewise USA ${ }^{\circledR}$ ) to local initiatives (e.g., on-site visits, cost share programs, chipper days) that encourage risk-reducing actions by property owners. These programs are increasingly important to create fire-adapted communities and share the burden of wildfire risk across resource-constrained organizations [6]. Despite their importance, it is often unclear how these programs affect household behavior, whether those at the highest risk are being reached, or if alternative 
outreach strategies might be more effective. Limited public resources, growing housing development in fire-prone areas_-known as the wildland-urban interface (WUI) - and increasing frequency and intensity of wildfires require cost-effective approaches that induce WUI residents to mitigate wildfire risk on their properties.

Evidence from the field of behavioral science suggests new strategies to influence individual behavior, as well as how effects vary for different populations [7,8]. These insights are generated through experiments that provide causal evidence on behavioral factors that can otherwise be difficult to observe [9]. Behavioral science and experimental design have potential to improve communications related to wildfire risk and to encourage mitigation behavior. Employing these tools through research-practice collaborations can improve program design, enhance our understanding of human behavior, and increase awareness of and engagement with local programs.

Here, we provide a brief overview of behavioral science and the application of its concepts and methods to household behavior related to wildfire risk. We describe an illustrative example in which researchers and practitioners collaborated to develop evidence-based outreach in wildfire-prone communities in western Colorado. Finally, we draw from this study to highlight the potential benefits of bringing behavioral science into wildfire research and practice.

\section{Linking Behavioral Science to the Wildfire Context}

Drawing from economics, psychology, and other social sciences, the field of behavioral science explores the "supposedly irrelevant factors" that influence judgement and behavior [10]. These factors include how a choice is framed, the default setting or status quo, simple reminders or personal commitments, and information on the behaviors of peers, among others [11]. Their effects have illuminated the unintentional programmatic "sludge" that impedes behavior change and a new suite of interventions that can help "nudge" people towards more socially desirable actions [12,13].

In recent years, behavioral science has been integrated into program and policy development. Theoretical insights have evolved to provide a toolkit for practitioners to identify barriers to and opportunities for changing behavior [8]. A range of organizations, including international institutions and national governments, have adopted behavioral science approaches to design and evaluate behavior-change programs [14-17]. These approaches employ field experiments to test changes to program design and outreach. For example, the U.S. Department of Agriculture tested the effect of simple reminder letters on landowner enrollment in the Conservation Reserve Program [18]. Municipal utilities have tested whether letters with personalized information or social comparisons affect household water and energy conservation $[19,20]$.

Behavioral science has clear relevance to household behavior and wildfire risk mitigation. Foundational research in the field focused on decision making under risk and how people deviate from the typical economic model of "rational" behavior. Researchers found that people often respond differently when a choice is framed as a loss compared to a gain [21]. For example, framing communications about forest and fuel management as a means to restore losses in forest health can be more persuasive than emphasizing improvements (gains) in forest health [22]. People sometimes struggle to evaluate small probability events, either over- or under-weighting their likelihood [23]. Research has shown people to be unrealistically optimistic about future events, including natural disasters [24,25]. This tendency may explain why some WUI residents view their properties' wildfire risk as lower than professionals do-a commonly observed "risk gap" [5]. People also often rely on mental shortcuts to evaluate probabilities and make decisions [26]. Vivid and familiar stories or emotional responses can act as shortcuts to guide a person's assessment of risk, such as homeowners' responses to wildfire information or policymakers' actions in allocating wildfire resources [27].

Research in behavioral science has also identified the effects of social influence in determining behavior [28,29]. Because wildfire risk is spatially interdependent (i.e., one property's risk affects and is affected by its neighbors), social factors, such as norms, reciprocity and recognition, may be relevant levers for behavioral change [30,31]. Indeed, programs to engage households in wildfire 
risk-reduction have incorporated social influence into their outreach by recognizing homeowners for adopting best practices or employing neighborhood ambassadors to share information. For example, Firewise Communities USA ${ }^{\circledR}$ provides designated communities a Firewise sign to post at community entrances. Boulder County Wildfire Partners, in Colorado, provides individual households with yard signs indicating that the property meets the program's standards. These programs recognize good behavior and make it observable to others-two strategies that have shown to increase pro-social behavior [32,33]. More research is needed to determine whether these programs generate additional risk mitigation or, conversely, have unintended effects that dissuade future mitigation work [34,35].

Despite resource constraints and a reliance on residents' voluntary participation, wildfire mitigation and education programs can be innovative and engage in cross-organization knowledge-sharing of "lessons learned" (e.g., Fire-Adapted Communities Learning Network, or FAC-NET). Such lessons are often based on the experiences of local experts that provide perspectives and anecdotes from the field, which do not lend themselves to quantitative effectiveness evaluations. An experimental approach, such as randomly assigning households to receive one version of outreach or another, enables programs to identify the causal effects of their outreach on behaviors they care about (e.g., [36-38]). Results can facilitate cost-effective program adaptation and provide a basis for interpreting the generalizability of results.

\section{Experimental Outreach in Wildfire-Prone Areas of Western COLORADO}

In this section, we describe a field experiment conducted in partnership with a wildfire organization to test behavioral outreach strategies and measure their effects. We present this experiment as an example drawn from an ongoing study to illustrate how insights from behavioral science can be used to understand wildfire risk mitigation program outreach.

Since 2012, the study coauthors have developed a productive research-practice partnership aimed at understanding and encouraging wildfire mitigation on private property. This partnership links social science researchers with the West Region Wildfire Council (WRWC), an organization that works across six counties in western Colorado to reduce wildfire risk on private properties (http://www.cowildfire.org). The region served by WRWC is primarily rural, where the majority of housing would be characterized as a wildland-urban intermix, sprawling into wooded and fire-adapted ecosystems [39]. This pattern matches nationwide growth in development in the wildland-urban interface [40]. Because each county and many communities within the WRWC region have developed Community Wildfire Protection Plans (CWPPs) as part of the growing importance of addressing wildfire on the landscape, the organization uses community risk measures from the CWPPs to guide their efforts. Other community-scaled risk measures, such as the Wildfire Risk to Communities tool (https://wildfirerisk.org/), could also provide community-level risk ratings.

WRWC provides community outreach and education, as well as direct technical and financial assistance to residents for reducing wildfire risk. Community-level risk ratings taken from the relevant CWPPs help guide WRWC decisions regarding which communities to focus resources. A "community" was defined by WRWC following the scale at which they administer wildfire risk mitigation efforts. As part of their programs, the organization conducts parcel-level rapid wildfire risk assessments (hereafter, rapid assessments) for residential properties in the communities within their service area. These rapid assessments provide a snapshot of a property's wildfire risk factors, including background fuels, defensible space, home hardening, and emergency access. Rapid assessments are conducted for all parcels with a structure greater than 800 square feet in a community, thus providing a disaggregated community risk map and baseline data on the most prevalent risk factors, guiding decisions about where to focus efforts within a community. When requested by residents, WRWC also conducts in-depth, on-site risk assessments that provide specific guidance on what needs to be done to mitigate wildfire risk to the home and property. The rapid assessments can serve as a precursor to the in-depth assessments. 
From 2013 to 2017, WRWC conducted several thousand rapid assessments. The information from these rapid assessments can be useful to homeowners if they are made aware of the information's availability. It can inform them of their property's overall risk, as well as the specific factors that contribute to the overall risk rating. However, as of 2015, WRWC only listed the rapid assessment data in static community documents and did not have a strategic plan for sharing the results with residents.

\subsection{Study Design}

From 2016 to 2019, WRWC mailed 4564 letters to property owners in six communities in western Colorado (Figure 1). Property owner names and mailing addresses were acquired from county assessors' records and matched with rapid assessment data. The letters directed recipients to visit personalized webpages to view their properties' risk factors. These webpages display each property's full rapid assessment results and direct homeowners to contact WRWC for support in conducting wildfire risk reduction (Figure S1).

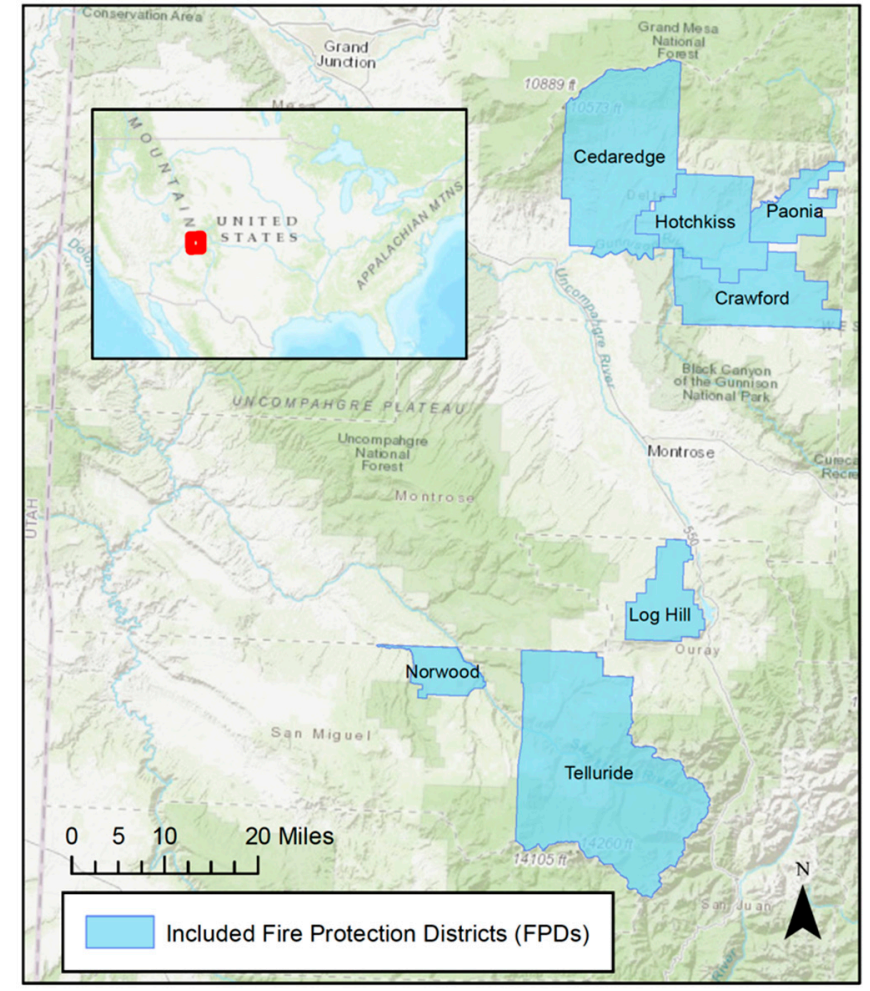

Figure 1. Western Colorado communities (FPDs) included in the experiment.

In order to test the effects of different outreach strategies, property owners were randomly assigned to receive one of three versions of the letter. These versions varied according to the risk information provided to the property owner: either only community risk as rated within the existing documents of the relevant CWPP (Control), community and parcel risk (Personalized Information), or community, parcel and average of nearest neighbors' risk (Social Comparison). See Figure S2 for an example of the letter.

Each letter included a unique code for a property owner to access their personalized rapid assessment webpage. These access codes enabled WRWC to track webpage visits at the user level, which served as the primary outcome measure for the study. Webpages also directed visitors to contact WRWC to schedule an in-depth wildfire risk assessment. These website visits serve as a proxy for interest in wildfire risk information and a measure of engagement with wildfire risk and programming. We acknowledge this as a small, but measurable, step in a broader spectrum of engagement that can help create fire-adapted communities [41]. 
Property owners were assigned to treatment using block random design to ensure balance across communities and properties of different risk ratings. We conducted Pearson's Chi-squared tests to evaluate differences in responses by community and between treatments.

\subsection{Results}

Overall, the mailed letters generated interest in risk information among some property owners, but only a small fraction (1/8th) of those who received the letters visited the website. In total, 590 letter recipients $(12.5 \%)$ visited their personalized webpages. Analysis of the response by treatment found no overall difference between the three different versions of the mailing $\left(\chi^{2}=0.45, p=0.80\right.$; Figure 2). Ongoing research will further investigate whether and how personalized information about a property's wildfire risk changes information-seeking among parcels with different risk levels.

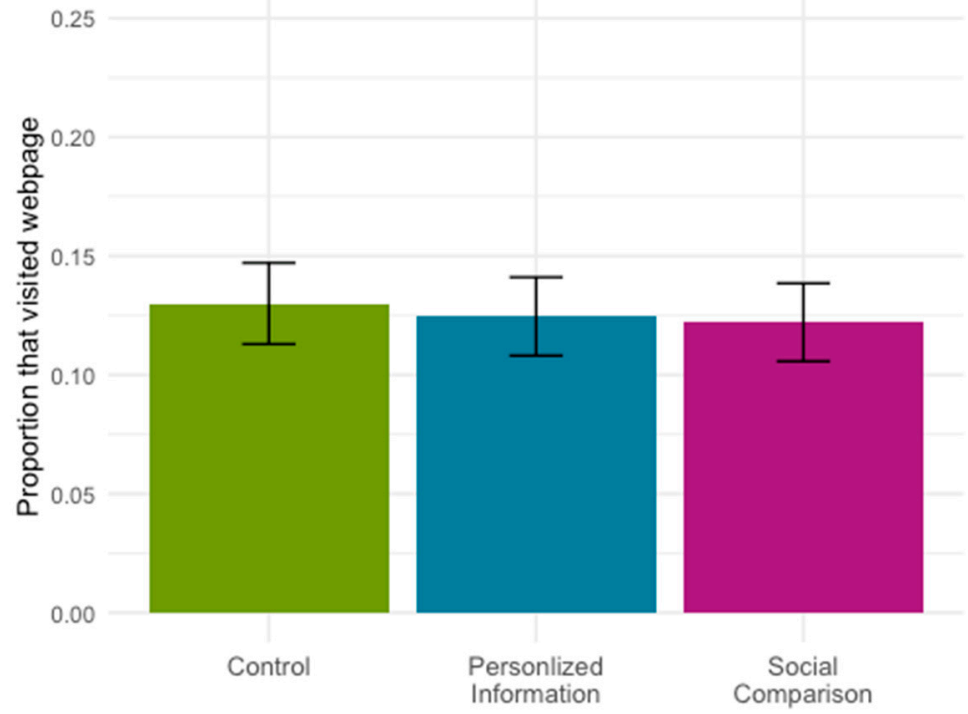

Figure 2. Webpage visits by treatment version: community risk (Control; $n=1492)$, community and parcel risk (Personalized Information; $\mathrm{n}=1541$ ), and community, parcel and neighbor risk (Social Comparison; $\mathrm{n}=1531)$. Error bars show $95 \%$ confidence interval.

We found that the overall response rate (as measured by website visitation) varied by community $\left(\chi^{2}=35.4, p<0.001\right)$. However, the treatments did not change responses within any communities (Table 1). The study design that linked access codes to webpage tracking allowed the organization to measure how much (or how little) interest their outreach generated, and how that interest varied by community.

Table 1. Summary of letters mailed and response rates (\%) by community and treatment.

\begin{tabular}{lccccccc}
\hline & Cedaredge & Crawford & Hotchkiss & Log Hill & Norwood & Paonia & Telluride \\
\hline Mailed Letters & 973 & 203 & 347 & 657 & 297 & 333 & 1754 \\
\hline Response Rate (\%) (Overall) & 17.5 & 9.4 & 9.5 & 10.5 & 15.2 & 8.1 & 12.0 \\
\hline Control & 18.8 & 10.6 & 9.1 & 10.0 & 20.3 & 9.2 & 11.8 \\
\hline Personalized Information & 15.4 & 10.6 & 8.2 & 11.0 & 14.0 & 8.3 & 13.0 \\
\hline Social Comparison & 18.2 & 7.0 & 11.3 & 10.5 & 13.2 & 6.7 & 11.1 \\
\hline$\chi^{2}$ Statistic * & 1.52 & 0.69 & 0.70 & 0.10 & 1.88 & 0.50 & 0.94 \\
\hline$p$-value * & 0.468 & 0.708 & 0.706 & 0.953 & 0.391 & 0.778 \\
\hline
\end{tabular}

* Chi-squared test statistics and $p$-values shown for differences between treatments within each community. 
While response rates may appear low, WRWC reported considerable interest in their programs in several of these communities following the mailing. In Cedaredge, for example, WRWC averaged less than two defensible space projects per year over the five years before the letters were sent; in the year following the mailing, WRWC was requested to conduct 17 projects. Although we are unable to connect this behavior directly to the letter, this shows an increase in action after the outreach. Future research may track more costly actions, like signing up for an in-depth risk assessment or a cost-share program, with mailings and webpage visits. Treatments will need to be tailored to address the particular barriers to those actions, which may include reducing paperwork or other frictions in participation [13].

\section{Benefits of Bridging Wildfire Research and Practice with Behavioral Science}

The behavioral and experimental approach described above has three potential benefits for wildfire research and practice.

First, embedding research in outreach can facilitate innovation in how organizations connect with their audiences. Increasingly, organizations are collecting parcel-level rapid wildfire risk assessment data. These existing data provide an opportunity to inform and engage residents, but organizations might not fully capitalize on opportunities to share it with property owners and learn about their programs in the process (Figure 3).

(a) COMMUNITY-LEVEL APPROACH

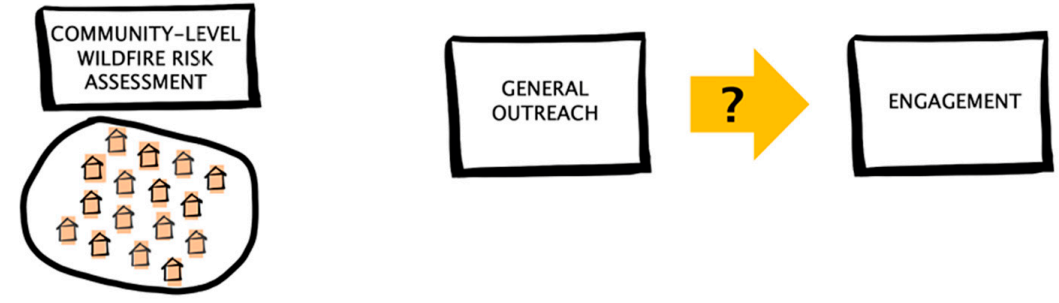

(b) PARCEL-LEVEL APPROACH
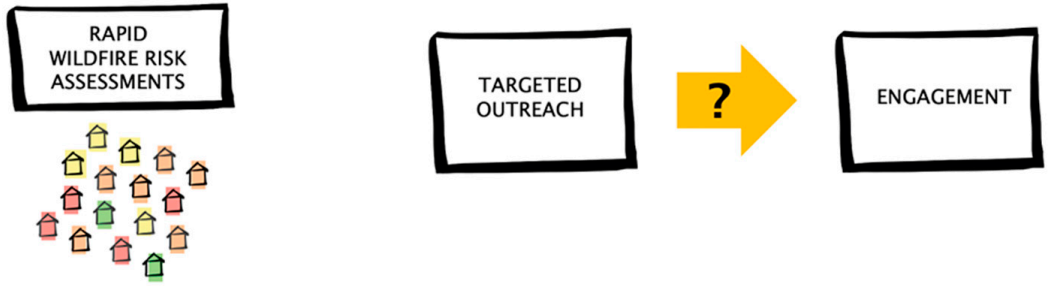

(c) EXPERIMENTAL APPROACH
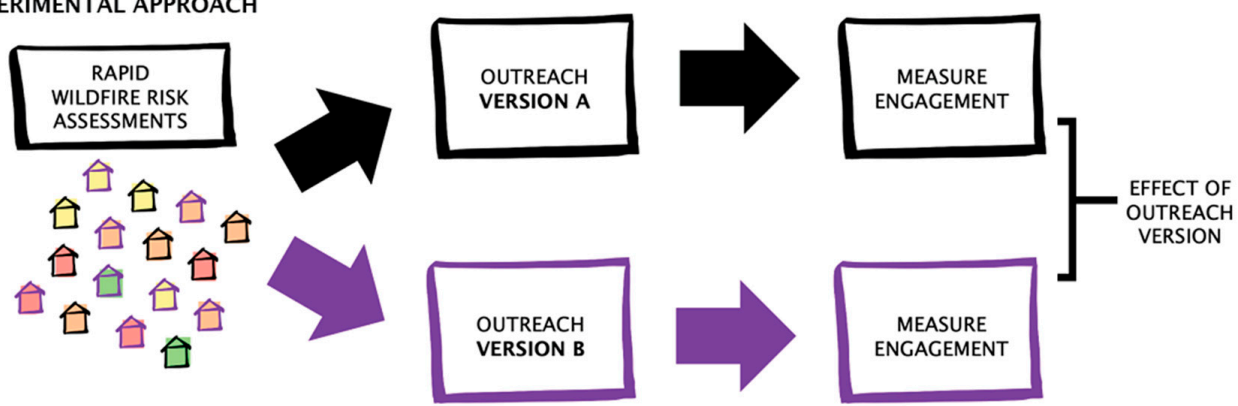

Figure 3. Three approaches to engaging homeowners in wildfire programs. (a) The Community-Level Approach relies on general community-level evaluations of risk and does not typically measure effects of outreach on residents' engagement. (b) In the Parcel-Level Approach, programs conduct rapid assessments and use these to target their outreach, but still do not monitor the effectiveness of outreach or residents' engagement. (c) The Experimental Approach embeds research into wildfire program delivery to leverage rapid assessment data in outreach, randomly assign households to different outreach versions, and measure differences in residents' engagement. 
In conceiving how to share WRWC's rapid assessment data, we developed two novel communication strategies: community-wide letters containing tailored risk information and personalized webpages. The outreach letters were mailed to all homeowners in a community, leveraging publicly available county assessor data for contact information. These community-wide mailings included personalized variable data, differing from the usual non-targeted direct mail approach. The content of the letter was deliberately designed to direct homeowner action towards a measurable outcome: visiting a personalized webpage describing risk information specific to the homeowner. The webpages were gated by unique codes, which enabled users to access individualized information, protected privacy, and tracked visitation. These websites provided a low-cost tool for sharing information with residents and encouraging subsequent mitigation behavior, such as signing up for an in-depth risk assessment. As with any outreach, it is important to consider how these communications strategies may have privileged certain groups over others (e.g., younger households with access to technology and internet). Adopting a behavioral and experimental approach can help organizations consider and measure how their outreach differentially affects their constituents and develop more targeted approaches. In the study described above, future research might explore how website visits varied by demographics or internet access and inform the selection of outreach methods to ensure that vulnerable populations are effectively served by wildfire programs.

Second, employing an experimental approach can generate evidence on the impacts of that outreach by testing different strategies. Rather than sending one version of the mailing, we tested three ways of communicating risk information. This process allowed us to ask how small, costless changes to outreach capture attention and generate interest among WUI residents. Such an approach provides the opportunity to address longstanding questions about what works in communicating risk, especially where behavioral science may offer new insights. There is a wealth of future research to explore questions and assumptions in the wildfire practitioner community, such as whether photos of flames engage or repel homeowners when communicating wildfire risk. We measured the effect of the letter and its variations on webpage visits. This outcome was tied directly to the outreach. Irrespective of the experimental differences, this approach allowed us to observe the behavior induced by the letter. Measuring outcomes of programmatic outreach is critical to effectiveness monitoring. Given the costly, infrequent and difficult-to-observe nature of wildfire mitigation on private property, it is important to identify and track intermediate actions (such as visiting a webpage or scheduling an in-depth risk assessment). These metrics can also be useful to wildfire organizations seeking to demonstrate their efforts and impact to funders.

Third, bridging research and practice can produce benefits for both. Researchers that partner with practitioners gain insights into the research context, feedback on questions and hypotheses, and results that are impactful beyond academia. Practitioners who are open to data-sharing and experimentation with researchers can learn and innovate in the process of conducting their programs. Research can be tailored to the realities of wildfire programs and their limitations, such as capacity and expected public acceptance of particular strategies, enabling both parties to pursue efforts that are relevant and useful in the real world.

This initial experiment has spurred interest among practitioners in other communities in the American West who hope to share individualized risk information with their constituents and learn about them in the process. It is our hope that future research-practice collaborations continue to incorporate behavioral and experimental approaches. Such collaboration requires balancing capacity, timelines, and goals, but can generate evidence to improve outreach and help WUI residents better prepare for wildfires.

Supplementary Materials: The following are available online at http://www.mdpi.com/2571-6255/3/4/66/s1. Figure S1: Screenshot of personalized risk assessment webpage. Figure S2: Examples of the letters mailed to property owners.

Author Contributions: Conceptualization, H.B., J.R.M., H.B.-S., P.C., J.G., L.F., and C.B.; data curation, J.R.M., J.G., and L.F.; writing—original draft, H.B.; writing-review and editing, H.B., J.R.M., H.B.-S., P.C., J.G., C.B., and L.F.; 
visualization, H.B. and J.M.; funding acquisition, J.R.M., H.B.-S., P.C. All authors have read and agreed to the published version of the manuscript.

Funding: This research was funded by the USDA Forest Service's National Center for Natural Resource Economics Research, National Science Foundation Grant SES-1823509, and in-kind by the authors' institutions.

Acknowledgments: We thank Elizabeth Palchak for helpful comments on this manuscript.

Conflicts of Interest: The authors declare no conflict of interest. The funders had no role in the design of the study; in the collection, analyses, or interpretation of data; in the writing of the manuscript, or in the decision to publish the results.

\section{References}

1. Cohen, J.D. Residential fire destruction during wildfires: A home ignition problem. In Modelling Fire Behaviour and Risk; Nuova StampaColor: Sassari, Italy, 2012.

2. Syphard, A.D.; Brennan, T.J.; Keeley, J.E. The role of defensible space for residential structure protection during wildfires. Int. J. Wildland Fire 2014, 23, 1165-1175. [CrossRef]

3. Brenkert-Smith, H.; Champ, P.A.; Flores, N. Trying Not to Get Burned: Understanding Homeowners' Wildfire Risk-Mitigation Behaviors. Environ. Manag. 2012, 50, 1139-1151. [CrossRef] [PubMed]

4. Brenkert-Smith, H.; Champ, P.A.; Flores, N. Insights Into Wildfire Mitigation Decisions Among Wildland-Urban Interface Residents. Soc. Nat. Resour. 2006, 19, 759-768. [CrossRef]

5. Meldrum, J.; Champ, P.A.; Warziniack, T.; Barth, C.M.; Falk, L.C.; Brenkert-Smith, H. Understanding Gaps Between the Risk Perceptions of Wildland-Urban Interface (WUI) Residents and Wildfire Professionals. Risk Anal. 2015, 35, 1746-1761. [CrossRef]

6. Calkin, D.E.; Cohen, J.D.; Finney, M.A.; Thompson, M.P. How risk management can prevent future wildfire disasters in the wildland-urban interface. Proc. Natl. Acad. Sci. USA 2014, 111, 746-751. [CrossRef]

7. Yoeli, E.; Budescu, D.V.; Carrico, A.R.; Delmas, M.A.; DeShazo, J.R.; Ferraro, P.J.; Forster, H.A.; Kunreuther, H.; Larrick, R.P.; Lubell, M.; et al. Behavioral science tools to strengthen energy \& environmental policy. Behav. Sci. Policy 2017, 3, 68-79. [CrossRef]

8. Madrian, B.C. Applying Insights from Behavioral Economics to Policy Design. Annu. Rev. Econ. 2014, 6, 663-688. [CrossRef]

9. Harrison, G.W.; List, J.A. Field Experiments. SSRN Electron. J. 2004, 42, 1009-1055. [CrossRef]

10. Thaler, R.H. Behavioral Economics: Past, Present, and Future. Am. Econ. Rev. 2016, 106, 1577-1600. [CrossRef]

11. Dolan, P.; Hallsworth, M.; Halpern, D.; King, D.; Metcalfe, R.; Vlaev, I. Influencing behaviour: The mindspace way. J. Econ. Psychol. 2012, 33, 264-277. [CrossRef]

12. Thaler, R.H. From Cashews to Nudges: The Evolution of Behavioral Economics. Am. Econ. Rev. 2018, 108, 1265-1287. [CrossRef]

13. Sunstein, C.R. Sludge Audits. Behav. Public Policy 2020, 1-20. [CrossRef]

14. World Bank. World Development Report 2015: Mind, Society, and Behavior; The World Bank: Washington, DC, USA, 2015; ISBN 978-1-4648-0342-0.

15. OECD. Tackling Environmental Problems with the Help of Behavioural Insights; OECD Publishing: Paris, France, 2017; ISBN 978-92-64-27386-3.

16. Obama, B. Executive Order-Using Behavioral Science Insights to Better Serve the American People; The White House: Washington, DC, USA, 2015.

17. Dolan, P.; Hallsworth, M.; Helpern, D.; King, D.; Vlaev, I. MINDSPACE: Influencing Behaviour through Public Policy; Institute for Government: London, UK, 2010.

18. Wallander, S.; Ferraro, P.J.; Higgins, N. Addressing Participant Inattention in Federal Programs: A Field Experiment with the Conservation Reserve Program. Am. J. Agric. Econ. 2017, 99, 914-931. [CrossRef]

19. Allcott, H. Social norms and energy conservation. J. Public Econ. 2011, 95, 1082-1095. [CrossRef]

20. Ferraro, P.J.; Price, M.K. Using Nonpecuniary Strategies to Influence Behavior: Evidence from a Large-Scale Field Experiment. Rev. Econ. Stat. 2013, 95, 64-73. [CrossRef]

21. Kahneman, D.; Tversky, A. Prospect Theory: An Analysis of Decision under Risk. Econometrica 1979, 47, 263-291. [CrossRef] 
22. Wilson, R.; Ascher, T.J.; Toman, E. The Importance of Framing for Communicating Risk and Managing Forest Health. J. For. 2012, 110, 337-341. [CrossRef]

23. Tversky, A.; Kahneman, D. Belief in the law of small numbers. Psychol. Bull. 1971, 76, 105-110. [CrossRef]

24. Shepperd, J.A.; Waters, E.A.; Weinstein, N.D.; Klein, W.M.P. A Primer on Unrealistic Optimism. Curr. Dir. Psychol. Sci. 2015, 24, 232-237. [CrossRef]

25. Suls, J.M.; Rose, J.P.; Windschitl, P.D.; Smith, A.R. Optimism Following a Tornado Disaster. Pers. Soc. Psychol. Bull. 2013, 39, 691-702. [CrossRef] [PubMed]

26. Tversky, A.; Kahneman, D. Judgment under Uncertainty: Heuristics and Biases. Science 1974, 185, $1124-1131$. [CrossRef] [PubMed]

27. Ascher, T.J.; Wilson, R.; Toman, E. The importance of affect, perceived risk and perceived benefit in understanding support for fuels management among wildland-urban interface residents. Int. J. Wildland Fire 2013, 22, 267-276. [CrossRef]

28. Nyborg, K.; Anderies, J.M.; Dannenberg, A.; Lindahl, T.; Schill, C.; Schluter, M.; Adger, W.N.; Arrow, K.J.; Barrett, S.; Carpenter, S.; et al. Social norms as solutions. Science 2016, 354, 42-43. [CrossRef] [PubMed]

29. Abrahamse, W.; Steg, L. Social influence approaches to encourage resource conservation: A meta-analysis. Glob. Environ. Chang. 2013, 23, 1773-1785. [CrossRef]

30. Brenkert-Smith, H.; Dickinson, K.L.; Champ, P.A.; Flores, N. Social amplification of wildfire risk: The role of social interactions and information sources. Risk Anal. 2013, 33, 800-817. [CrossRef] [PubMed]

31. Dickinson, K.; Brenkert-Smith, H.; Champ, P.; Flores, N. Catching Fire? Social Interactions, Beliefs, and Wildfire Risk Mitigation Behaviors. Soc. Nat. Resour. 2015, 28, 807-824. [CrossRef]

32. Ariely, D.; Bracha, A.; Meier, S. Doing Good or Doing Well? Image Motivation and Monetary Incentives in Behaving Prosocially. Am. Econ. Rev. 2009, 99, 544-555. [CrossRef]

33. Yoeli, E.; Hoffman, M.; Rand, D.G.; Nowak, M.A. Powering up with indirect reciprocity in a large-scale field experiment. Proc. Natl. Acad. Sci. USA 2013, 110, 10424-10429. [CrossRef]

34. Kramer, A.; Mockrin, M.H.; Alexandre, P.M.; Stewart, S.I.; Radeloff, V.C. Where wildfires destroy buildings in the US relative to the wildland-urban interface and national fire outreach programs. Int. J. Wildland Fire 2018, 27, 329-341. [CrossRef]

35. Blanken, I.; Van De Ven, N.; Zeelenberg, M. A Meta-Analytic Review of Moral Licensing. Pers. Soc. Psychol. Bull. 2015, 41, 540-558. [CrossRef]

36. Jayachandran, S.; De Laat, J.; Lambin, E.F.; Stanton, C.Y.; Audy, R.; Thomas, N.E. Cash for carbon: A randomized trial of payments for ecosystem services to reduce deforestation. Science 2017, 357, 267-273. [CrossRef] [PubMed]

37. Milkman, K.L.; Beshears, J.; Choi, J.J.; Laibson, D.; Madrian, B.C. Using implementation intentions prompts to enhance influenza vaccination rates. Proc. Natl. Acad. Sci. USA 2011, 108, 10415-10420. [CrossRef] [PubMed]

38. Thaler, R.H.; Benartzi, S. Save More Tomorrow ${ }^{\mathrm{TM}}$ : Using Behavioral Economics to Increase Employee Saving. J. Polit. Econ. 2004, 112, S164-S187. [CrossRef]

39. Stewart, S.I.; Radeloff, V.C.; Hammer, R.B.; Hawbaker, T.J. Defining the Wildland-Urban Interface. J. For. 2007, 105, 201-207.

40. Radeloff, V.C.; Helmers, D.P.; Kramer, H.A.; Mockrin, M.H.; Alexandre, P.M.; Bar-Massada, A.; Butsic, V.; Hawbaker, T.J.; Martinuzzi, S.; Syphard, A.D.; et al. Rapid growth of the US wildland-urban interface raises wildfire risk. Proc. Natl. Acad. Sci. USA 2018, 115, 3314-3319. [CrossRef]

41. Paveglio, T.B.; Edgeley, C.M. Fire Adapted Community. In Encyclopedia of Wildfires and Wildland-Urban Interface (WUI) Fires; Manzello, S.L., Ed.; Springer International Publishing: Cham, Switzerland, 2019; pp. 1-9, ISBN 978-3-319-51727-8.

Publisher's Note: MDPI stays neutral with regard to jurisdictional claims in published maps and institutional affiliations.

Licensee MDPI, Basel, Switzerland. This article is an open access article distributed under the terms and conditions of the Creative Commons Attribution (CC BY) license (http://creativecommons.org/licenses/by/4.0/). 